REIS HF; MELO CM; MELO EP; SILVA RA; SCALON SPQ. 2014. Conservação pós-colheita de alface crespa, de cultivo orgânico e convencional, sob atmosfera modificada. Horticultura Brasileira 32: 303-309. DOI - http://dx.doi.org/10.1590/S0102-05362014000300011

\title{
Conservação pós-colheita de alface crespa, de cultivo orgânico e convencional, sob atmosfera modificada
}

\author{
Héber F Reis; Caio M Melo; Evandro P Melo; Rafael A Silva; Silvana PQ Scalon \\ UFGD-FCA, Lab. Fisiologia Vegetal, C. Postal 533, 79804-970 Dourados-MS; heber.f.reis@gmail.com; caio_marsura@hotmail.com; \\ evandropuhlm@hotmail.com; rafa_azevedo15@hotmail.com; silvanascalon@ufgd.edu.br
}

\section{RESUMO}

Hortaliças folhosas são altamente suscetíveis à perda de água e degradação da clorofila, com reflexos na redução de tamanho, massa, teor de sólidos solúveis e vitamina $\mathrm{C}$, o que pode ser intensificado pelo manejo inadequado da temperatura e da umidade do ar nos locais de armazenamento e comercialização, com redução de vida de prateleira e aumento do custo final do produto para o consumidor. O objetivo deste trabalho foi avaliar a qualidade pós-colheita de alface tipo crespa, cv. Isabela, de cultivo orgânico e convencional, acondicionadas em diferentes embalagens e armazenadas sob refrigeração por diferentes períodos. O ensaio foi conduzido na UFGD, em Dourados-MS. Foi utilizado o delineamento experimental inteiramente casualizado com quatro repetições, com esquema fatorial $2 \times 3 \times 4$ sendo: orgânico ou convencional, em três tipos de embalagens de polietileno (totalmente aberta, parcialmente fechada e totalmente fechada) e quatro períodos de avaliação $\left(0 ; 5 ; 10\right.$ e 15 dias) e armazenamento em câmara a $5^{\circ} \mathrm{C}$, com umidade relativa de $90 \% \pm \mathrm{SD}$, na ausência de luz. Os parâmetros avaliados foram qualidade aparente, massa fresca, teores de clorofila, sólidos solúveis (SS), acidez titulável (AT) e ácido ascórbico (AA). As alfaces produzidas em cultivo orgânico conservaram por mais tempo a qualidade aparente, em relação às produzidas convencionalmente, com valores de SS e AT maiores, no final do armazenamento, embora com redução no teor de AA, mas sem diferenças para perda de clorofila e nas variações do $\mathrm{pH}$. A embalagem totalmente fechada demonstrou ser mais eficaz em reduzir a perda de massa fresca e conservar a qualidade aparente por mais tempo.

Palavras-chave: Lactuca sativa, sistemas de cultivo, embalagem, vida útil.

\begin{abstract}
Post-harvest conservation of crisp lettuce under modified atmosphere, cultivated on organic and conventional system

Leafy lettuce is highly susceptible to water loss, which can be intensified by inadequate management of temperature and air humidity during storage and commercialization, reducing shelf life and increasing the final cost of the product to the consumer. The aim of this study was to evaluate the post-harvest quality of crisp lettuce, cv. Isabela, cultivated on conventional and organic farming, packed in different packaging and stored under refrigeration during different periods. The assay was carried out in the Universidade Federal da Grande Dourados, in Dourados, Mato Grosso do Sul state, Brazil. The experimental design was complete randomized blocks with four replications, in a factorial scheme $2 \times 3 \times 4$ : organic or conventional cultivation, three types of polyethylene packagings (fully open, partially closed and fully closed) and four evaluation periods $(0 ; 5$; 10 and 15 days). Lettuce was stored in a chamber at $5^{\circ} \mathrm{C}$, relative humidity of $90 \% \pm \mathrm{SD}$, in the absence of light. We evaluated the apparent quality, fresh mass, chlorophyll content, soluble solids (SS), titratable acidity (TA) and ascorbic acid (AA). Lettuce produced in organic farming conserved for more time the apparent quality, in comparison to that produced in conventional farming, with higher values of SS and TA after storage, although with reduction of AA, but with no difference of chlorophyll loss and $\mathrm{pH}$ values. The fully closed packaging has proven to be more effective in reducing the fresh mass loss and to keep the apparent quality for more days.
\end{abstract}

Keywords: Lactuca sativa, farming system, packaging, shelf life.

(Recebido para publicação em 21 de novembro de 2013; aceito em 4 de junho de 2014) (Received on November 21, 2013; accepted on June 4, 2014)

\begin{abstract}
$\mathrm{A}^{\mathrm{a}}$ alface (Lactuca sativa) é uma das hortaliças mais populares e consumidas no Brasil, por sua facilidade de aquisição e produção durante o ano inteiro (Henz \& Suinaga, 2009; Sala \& Costa, 2012). Também destaca-se entre as hortaliças folhosas mais consumidas em todo mundo devido a sua importância alimentar como fonte de vitaminas e sais minerais (Santi et al., 2010), sendo rica em folato, com boa quantidade de betacaroteno, vitamina $\mathrm{C}$, potássio e certos fitoquímicos, como os flavonóides e
\end{abstract}

lactucina (Chitarra \& Chitarra, 2005).

Tão importante quanto a composição de nutrientes é também a segurança de alimentos, os quais devem ser livres de toda e qualquer substância química, natural ou contaminante, causadora de danos à saúde do consumidor (Chitarra \& Chitarra, 2005). A segurança alimentar pode ser obtida através de produtos orgânicos, cultivados sem o uso de fertilizantes e defensivos químicos, que não agridem o meio ambiente e não apresentam riscos a saúde do consumi- dor (Guadagnin et al., 2005; Marchiori, 2006; Sampaio et al., 2008 ).

Além da qualidade nutricional e segurança alimentar, há de se considerar a conservação da qualidade aparente do produto após a colheita pois, segundo Kays (1999), é o primeiro critério utilizado pelo consumidor no julgamento da qualidade das hortaliças. A aparência é caracterizada pelo tamanho, forma, cor, ausência de desordens mecânicas, fisiológicas e patológicas nas hortaliças.

Hortaliças folhosas são altamente 
suscetíveis à perda de água, o que pode ser intensificado pelo manejo inadequado da temperatura e da umidade do ar nos locais de armazenamento e comercialização, com redução da vida de prateleira e aumento do custo final do produto para o consumidor (Álvares et al., 2007).

Condições ambientais desejadas para a conservação pós-colheita de produtos vegetais podem ser obtidas através do controle de temperatura, da circulação de ar e da umidade relativa. Assim sendo, destacam-se como principais objetivos do armazenamento a redução da atividade biológica do produto e a redução do crescimento de microrganismos, com redução da temperatura ambiente, assim como a redução na transpiração, pela diminuição das diferenças entre a temperatura do ar e a do produto, bem como mantendo-se elevada umidade no ambiente (Chitarra \& Chitarra, 2005).

A manutenção da qualidade e consequentemente a extensão pós-colheita da alface, pode ser obtida com o uso de atmosfera modificada e/ou controlada. $\mathrm{O}$ armazenamento sob Atmosfera Controlada (AC) consiste no prolongamento da vida pós-colheita de produtos por meio da modificação e controle dos gases no meio do armazenamento, principalmente das concentrações de $\mathrm{O}_{2}$ e $\mathrm{CO}_{2}$. No armazenamento sob Atmosfera Modificada (AM), a atmosfera ambiente é geralmente alterada pelo uso de filmes plásticos, permitindo que a concentração de $\mathrm{CO}_{2}$ aumente e a de $\mathrm{O}_{2}$ diminua, com o processo respiratório. Nesse tipo de armazenamento, as concentrações de $\mathrm{O}_{2} \mathrm{e}$ $\mathrm{CO}_{2}$ não são controladas, e variam com o tempo, temperatura, tipo de filme e com a taxa respiratória do produto (Chitarra \& Chitarra, 2005). Esta técnica, além de reduzir a atividade respiratória aumenta a umidade relativa, diminuindo, assim, a perda de água por transpiração, e conseqüentemente o murchamento (Amarante et al., 2001).

Muitos filmes plásticos com diferentes permeabilidades a gases são empregados em frutos e hortaliças, tais como o polietileno de baixa densidade (PEBD) (Mello et al., 2003), o cloreto de polivinila (PVC) (Mota et al., 2006) e o tereftalato de polietileno (PET) (Álvares et al., 2010).
Segundo Henz \& Suinaga (2009), a alface do tipo crespa, além de ser apreciada na forma de salada, tem sido muito utilizada por redes de fast food como ingrediente de sanduíches por sua crocância, textura e sabor. Além destas características, segundo Silva et al. (2011), deve ser produzida preferencialmente de forma orgânica, a fim de proporcionar ao consumidor um produto de melhor qualidade, pela ausência de adubos e defensivos químicos. No entanto, são poucas as informações quanto à conservação pós-colheita de alface crespa de cultivo convencional e orgânico. Este trabalho teve por objetivo avaliar a qualidade em pós-colheita da alface tipo crespa, cultivar Isabela, produzida sob cultivo orgânico ou convencional, acondicionada em diferentes embalagens e armazenadas sob refrigeração.

\section{MATERIAL E MÉTODOS}

Alfaces do tipo crespa, cultivar Isabela, foram adquiridas de um produtor orgânico e de um produtor tradicional, em Dourados-MS. Em seguida, as alfaces foram levadas ao laboratório de pós-colheita da Universidade Federal da Grande Dourados onde foram lavadas em água corrente, para retirada do calor de campo e das impurezas, e higienizadas em solução clorada a 200 ppm por 10 minutos, sendo posteriormente preparadas de acordo com cada tratamento.

Foi utilizado o delineamento experimental inteiramente casualizado com quatro repetições, com esquema fatorial $2 \times 3 \times 4$, sendo dois tipos de cultivo (orgânico ou convencional) $x$ três tipos de embalagens plásticas de polietileno de baixa densidade [totalmente aberta (TA), parcialmente fechada (PF) e totalmente fechada (TF)] x quatro períodos de avaliação ( $0 ; 5 ; 10$ e 15 dias). As embalagens plásticas utilizadas foram sacos de polietileno de baixa densidade (PEBD), em que: TA eram totalmente abertas em uma das extremidades; em TF eram seladas nas duas extremidades, com dimensões de 30x36 cm e sem perfurações e, em PF eram seladas nas duas extremidades, com dimensões de 30x33 $\mathrm{cm}$ e furos de $1 \mathrm{~mm}$ espaçados a cada $0,5 \mathrm{~cm}$. As alfaces foram acondicionadas inteiras, uma cabeça por embalagem, e armazenadas em câmara fria a $5^{\circ} \mathrm{C}$, com umidade relativa de $90 \% \pm \mathrm{SD}$, na ausência de luz.

Os dados foram submetidos à análise de variância e havendo significância as médias de tipo de cultivo e embalagens foram comparadas pelo teste de Tukey e as dos períodos de avaliação e suas interações com os outros tratamentos foram ajustadas por análise de regressão, ambos a 5\% de probabilidade, utilizando-se o programa Sanest. Os dados de qualidade aparente foram apresentados apenas de maneira descritiva.

Foram avaliadas as características de 1) Qualidade aparente, avaliada através do percentual de área foliar deteriorada por uma escala de notas de 0 a $4(0=$ sem deterioração; $1=$ até $5 \%$ de área foliar deteriorada; $2=$ até $15 \%$ de área foliar deteriorada; $3=$ até $25 \%$ de área foliar deteriorada e $4=$ mais de $25 \%$ de área foliar deteriorada); 2) Índice de clorofila, obtido através de leitura direta com o auxílio de um clorofilômetro digital da marca KONICA MINOLTA modelo SPAD 502; 3) Massa fresca, todas as amostras foram pesadas a cada período de avaliação em balança analítica (marca BEL, modelo MARK M503, com três casas decimais) para obtenção tanto da massa fresca quanto de sua perda.

Para as avaliações bioquímicas, 100 g de cada repetição foi triturada com 200 $\mathrm{mL}$ de água destilada e filtrada obtendo-se um extrato inicial. 4) pH - medido com peagâmetro digital da marca Hanna Instruments, modelo HI 2221, após imersão direta do eletrodo na solução de extrato inicial. 5) Acidez titulável (AT) - três amostras de $5 \mathrm{~g}$ do extrato inicial foram misturadas em $100 \mathrm{~mL}$ de água destilada e tituladas com $\mathrm{NaOH}$ a 0,01 $\mathrm{M}$ até $\mathrm{pH} 8,2$, com auxílio de peagâmetro (marca HANNA, modelo HI2221). Os resultados foram expressos em percentagem (\%) de ácido cítrico, v/m (IAL, 1985); 6) Sólidos solúveis (SS) - determinados por leitura direta em refratômetro digital (Instrutherm, modelo RTD-45, com valor corrigido para $20^{\circ} \mathrm{C}$ ); 7) Ácido Ascórbico (AA) avaliado conforme o método padrão da AOAC (1990): três amostras de 10 mL de polpa do extrato inicial foram trans- 
feridas para balões volumétricos de 100 $\mathrm{mL}$ e o volume completado com ácido oxálico a $1 \%$. Após a homogeneização, a solução foi filtrada em papel de filtro e em seguida tomou-se $10 \mathrm{~mL}$, em triplicata, para a titulação com diclorofenol indofenol de sódio. Os resultados foram expressos em mg de ácido ascórbico por $100 \mathrm{~g}$ de amostra.

\section{RESULTADOS E DISCUSSÃO}

Com relação à qualidade aparente, as alfaces de cultivo convencional em embalagens totalmente fechadas (TF) se conservaram isentas de deterioração até o quinto dia de armazenamento (Tabela 1). O perfil de qualidade aparente em embalagens TA foi semelhante ao obtido por Rezende et al. (2007) que, ao avaliarem a influência de épocas de plantio e doses de silício sobre o rendimento e qualidade pós-colheita da alface tipo americana cv. Raider, a $5 \pm 2^{\circ} \mathrm{C}$ por $10 \mathrm{e}$ 20 dias, constataram leve deterioração após 10 dias.

Nas cultivadas organicamente, a isenção de deterioração se manteve até o décimo dia com o uso de embalagens PF e TF. Resultados semelhantes também foram obtidos por Mello et al. (2003), ao conservarem alface americana minimamente processada em sacos de polietileno de baixa densidade a $4^{\circ} \mathrm{C}$ por dez dias, constatando que as produzidas em cultivo orgânico foram superiores, em todos os atributos sensoriais testados, comparado às produzidas de maneira convencional, o que foi atribuído ao fato da alface orgânica desencadear processos de natureza química e enzimática mais lentamente que a alface convencional.

Quanto à perda de água, a mesma aumentou com o período de armazenamento, independente do tipo da embalagem e cultivo (Tabela 2). No entanto, verificou-se maiores perdas nas embalagens TA e menores nas TF. Nas embalagens TA, a perda de água pelo cultivo orgânico foi significativamente menor em relação ao convencional em 5 dias de armazenamento, mas não diferiram significativamente no $10^{\circ}$ e $15^{\circ}$ dias. Nas embalagens $P F$, não houve diferenças significativas em 5 e 10 dias

Tabela 1. Qualidade aparente de plantas de alface, cv. Isabela, de cultivo orgânico e convencional, armazenadas a $4^{\circ} \mathrm{C}$ e $90-95 \%$ UR, em embalagens totalmente aberta (TA), parcialmente fechada (PF) e totalmente fechada (TF), sob diferentes períodos [apparent quality of lettuce plants, cv. Isabela, conventional and organic farming, stored at $4^{\circ} \mathrm{C}$ and $90-95 \% \mathrm{RH}$, in packages fully open (FO), partially closed (PC) and fully closed (FC), under different periods]. Dourados, UFGD, 2012.

\begin{tabular}{|c|c|c|c|c|}
\hline \multirow{2}{*}{$\begin{array}{l}\text { Tempo de armazenamento } \\
\text { (dias) }\end{array}$} & \multirow{2}{*}{ Cultivo } & \multicolumn{3}{|c|}{ Embalagens } \\
\hline & & TA & PF & TF \\
\hline \multirow{2}{*}{0} & Convencional & $0 *$ & 0 & 0 \\
\hline & Orgânico & 0 & 0 & 0 \\
\hline \multirow{2}{*}{05} & Convencional & 1 & 1 & 0 \\
\hline & Orgânico & 0 & 0 & 0 \\
\hline \multirow{2}{*}{10} & Convencional & 2 & 2 & 1 \\
\hline & Orgânico & 1 & 0 & 0 \\
\hline \multirow{2}{*}{15} & Convencional & 3 & 2 & 2 \\
\hline & Orgânico & 2 & 1 & 1 \\
\hline
\end{tabular}

*Nível de deterioração de área foliar por uma escala de notas de 0 a 4 ( $0=$ sem deterioração; $1=$ até $5 \%$ de área foliar deteriorada; $2=$ até $15 \%$ de área foliar deteriorada; $3=$ até $25 \%$ de área foliar deteriorada e $4=$ mais que $25 \%$ de área foliar deteriorada) [level of foliar area deterioration using a scale of grades from 0 to $4(0=$ no deterioration; $1=$ up to $5 \%$ of deteriorated foliar area; $2=$ up to $15 \%$ of deteriorated foliar area; $3=$ up to $25 \%$ of deteriorated foliar area and, $4=$ over $25 \%$ of deteriorated foliar área) $]$.

Tabela 2. Médias percentuais de perda de água e médias gerais dos teores de Sólidos Solúveis (SS), em ${ }^{\circ}$ Brix, obtidas em alfaces da cv. Isabela, produzidas sob cultivo orgânico ou convencional, avaliadas após 5; 10 e 15 dias de armazenamento a $4^{\circ} \mathrm{C}$ e $90-95 \%$ UR, em embalagens totalmente aberta (TA), parcialmente fechada (PF) e totalmente fechada (TF) [percentage of average water loss and general average levels of Soluble Solids (SS), in ${ }^{\circ}$ Brix, obtained in lettuce cv. Isabela, produced under conventional or organic farming, evaluated after $5 ; 10$ and 15 days of storage at $4{ }^{\circ} \mathrm{C}$ and $90-95 \% \mathrm{RH}$, in packages fully open (FO), partially closed (PC) and fully closed (FC)]. Dourados, UFGD, 2012.

\begin{tabular}{|c|c|c|c|c|}
\hline \multirow{2}{*}{$\begin{array}{l}\text { Tempo de armazenamento } \\
\text { (dias) }\end{array}$} & \multirow{2}{*}{ Cultivo } & \multicolumn{3}{|c|}{ Perda de água (\%) } \\
\hline & & TA & PF & TF \\
\hline \multirow{2}{*}{5} & Orgânico & $6,667 b^{*}$ & $1,303 \mathrm{a}$ & $0,000 \mathrm{a}$ \\
\hline & Convencional & $17,351 \mathrm{a}$ & $1,016 \mathrm{a}$ & $0,000 \mathrm{a}$ \\
\hline \multirow{2}{*}{10} & Orgânico & $15,017 \mathrm{a}$ & $5,346 \mathrm{a}$ & $0,020 \mathrm{a}$ \\
\hline & Convencional & $17,833 \mathrm{a}$ & $4,841 \mathrm{a}$ & $0,091 \mathrm{a}$ \\
\hline \multirow{2}{*}{15} & Orgânico & $26,708 \mathrm{a}$ & $10,913 \mathrm{~b}$ & $0,011 \mathrm{~b}$ \\
\hline & Convencional & $21,865 \mathrm{a}$ & $15,057 \mathrm{a}$ & $2,636 \mathrm{a}$ \\
\hline SST $\left({ }^{\circ}\right.$ Brix $)$ & & $1,340 \mathrm{~A}$ & $1,234 \mathrm{AB}$ & $1,175 \mathrm{~B}$ \\
\hline CV $(\%)$ & & & 23,756 & 0,150 \\
\hline
\end{tabular}

*Médias transformadas segundo arco seno da raiz de $\mathrm{x} / 100$ (average values processed according to arcsine of $\mathrm{x} / 100$ root). Médias seguidas pela mesma letra, minúscula na coluna e maiúscula na linha, não diferem estatisticamente entre si pelo teste de Tukey $(p<0,05)$ [average values followed by same letter, lowercase in the column and uppercase in line, do no differ by Tukey test $(\mathrm{p}<0.05)]$.

de armazenamento, mas no $15^{\circ}$ dia a perda de água pelo cultivo orgânico foi significativamente menor em relação ao convencional. Comportamento semelhante ocorreu nas embalagens TF, com diferença significativa somente no $15^{\circ}$ dia, com média de perda de água menor no cultivo orgânico em relação ao convencional.

Na Figura 1A verifica-se que o cultivo orgânico apresentou perda de água, de forma progressiva, com o aumento do período de armazenamento, tendo sido maior para embalagens TA, interme- 


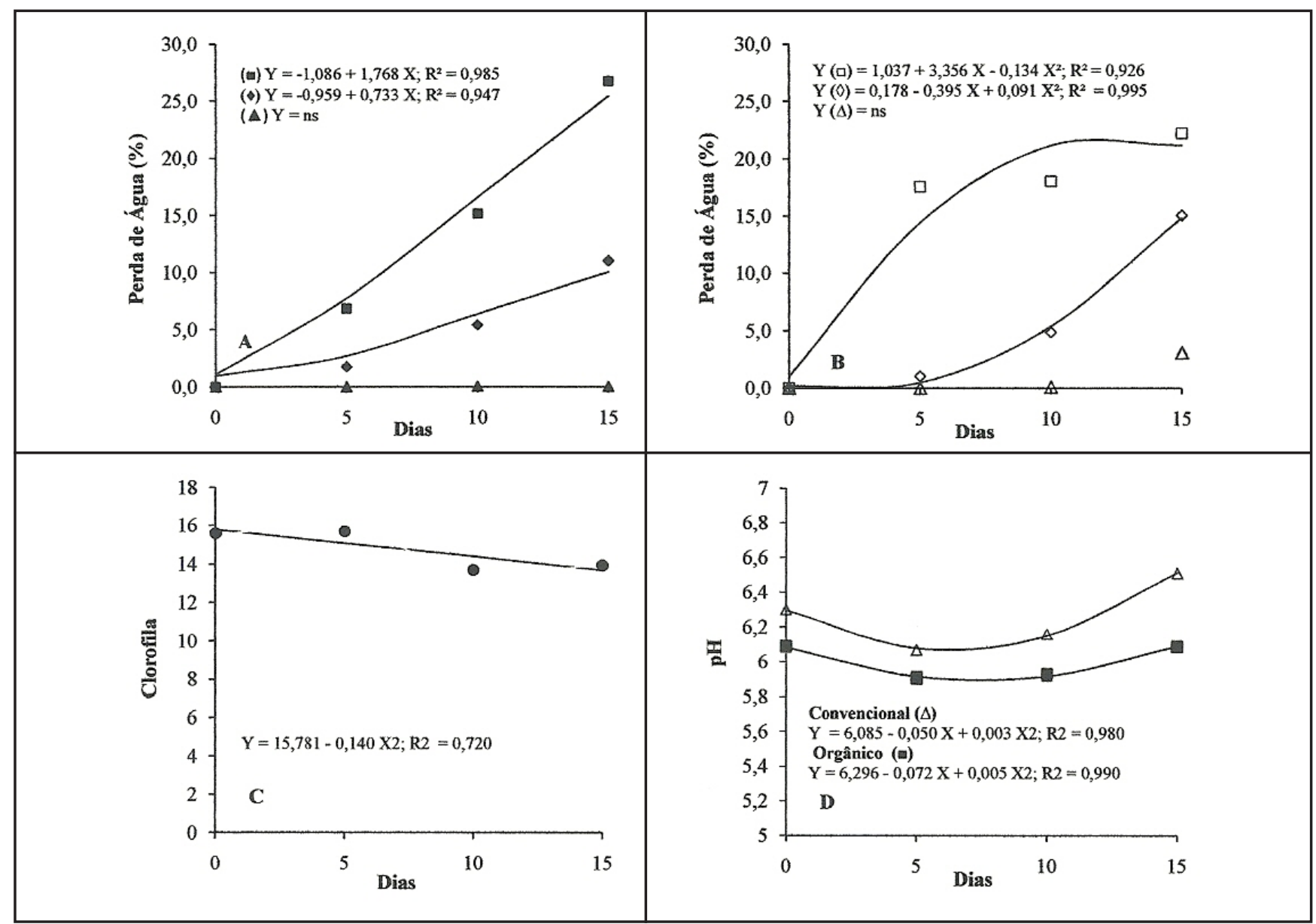

Figura 1. Perda de água (A e B), teor de clorofila (C) e pH (D) de plantas de alface crespa, cv. Isabela, de cultivo orgânico e convencional, armazenadas a $4^{\circ} \mathrm{C}$ e $90-95 \%$ UR, em embalagens totalmente abertas ( $\left.\mathbf{(}\right)$, parcialmente fechadas ( $)$ e totalmente fechadas ( $\left.\mathbf{\Delta}\right)$ [water loss (A and B), chlorophyll content (C) and $\mathrm{pH}(\mathrm{D})$ of crisp lettuce plants, cv. Isabela, in organic and conventional farming, stored at $4^{\circ} \mathrm{C}$ and 90-95\% relative humidity, fully open packaging ( $\mathbf{\square})$, partially closed ( $\bullet$ ) and fully closed ( $\boldsymbol{\Delta})$, for different periods]. Dourados, UFGD, 2012.

diária para $\mathrm{PF}$ e menor ou praticamente inexistente para TF. Pela Figura 1B, verifica-se que a perda de água pelo cultivo convencional, em comparação com o orgânico, foi mais intensa com as embalagens TA, tendo-se nestas estabilizado a partir do décimo dia. Com as embalagens PF a perda de água ocorreu a partir do quinto dia, sendo mais intensa a partir do décimo dia; com TF verifica-se a não ocorrência de perdas nos três períodos de armazenamento.

Resultados semelhantes ao do presente trabalho foram também obtidos por Mota et. al. (2006), ao constatarem que o uso de atmosfera modificada, no caso o PVC, proporcionou menor perda de massa fresca e maior teor relativo de água ao longo do armazenamento, em condição ambiente, para todas as cultivares de quiabo estudadas em relação às não embaladas com filme. De acordo com esses autores, a embalagem com PVC proporcionou menor gradiente de pressão de vapor entre a atmosfera interna e a superfície do fruto. Além disso, as condições de atmosfera modificada reduziram a concentração de oxigênio em relação à atmosfera normal, diminuindo a respiração e aumentando a conservação pós-colheita.

Quanto ao teor de clorofila, constatou-se um decréscimo de $12,5 \%$ ao longo do período de armazenamento até o $15^{\circ}$ dia, independente do tipo de cultivo e embalagem (Figura 1C). Esta redução foi relativamente baixa se comparada aos resultados obtidos por Morais et al. (2011) os quais, ao avaliarem a concentração de clorofila em alface hidropônica armazenada sob refrigeração $\left(7,6 \pm 1^{\circ} \mathrm{C}\right.$ e $27 \pm 5 \%$ UR), verificaram uma redução de $21,47 \%$ em quatro dias de armazenamento.
Neste caso, de acordo com Álvares \& Negreiros (2010) as condições de armazenamento como temperatura mais alta e a baixa umidade relativa contribuíram para uma maior taxa de degradação do pigmento. Segundo Park et al. (1999), um dos sintomas da senescência pós-colheita nas hortaliças folhosas é a perda de cor verde e a temperatura é o fator crítico principal da taxa de degradação da clorofila.

Resultados semelhantes aos do presente trabalho, com baixa degradação de clorofila, foram também obtidos por França (2011), ao ter embalado com plástico de polietileno perfurado cabeças de alface do tipo repolhuda crespa, variedade Lucy Brown, e do tipo solta lisa, variedade Vitória de Santo Antão, armazenadas a $5^{\circ} \mathrm{C}$ e $55 \%$ UR e a $22^{\circ} \mathrm{C}$ e $42 \%$ de UR, por 2 dias. Este autor não verificou alterações visíveis na cor verde 


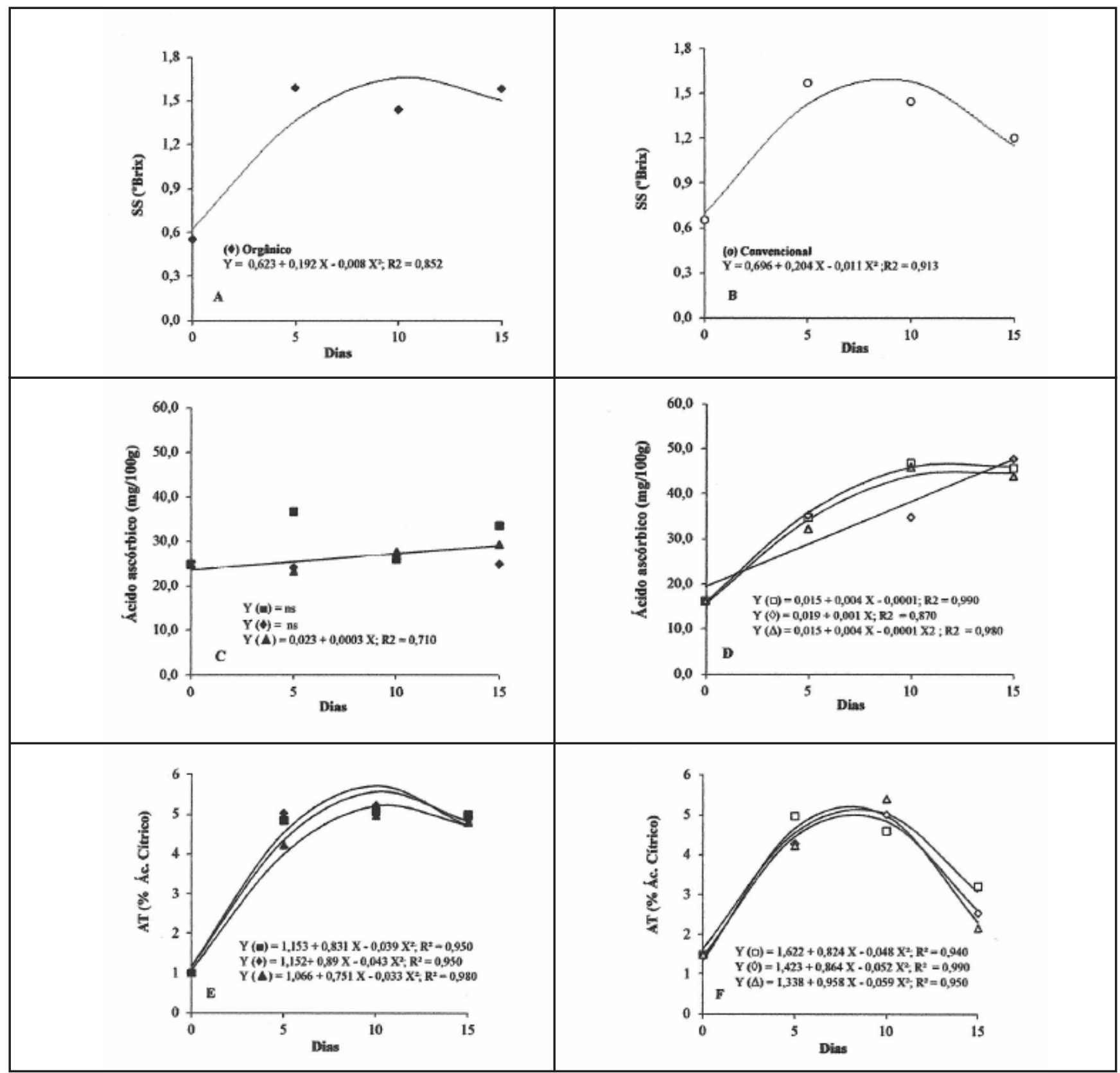

Figura 2. Teores de sólidos solúveis (SS) (A e B), ácido ascórbico (C e D) e acidez titulável (AT) (E e F) em plantas de alface crespa, cultivar Isabela, cultivadas orgânicamente (símbolo cheio) ou convencional (símbolo vazio), armazenadas a $4^{\circ} \mathrm{C}$ e $90-95 \%$ UR, em embalagens totalmente abertas $(\boldsymbol{\square})$, parcialmente fechadas $(\downarrow)$ e totalmente fechadas $(\boldsymbol{\Delta})$ [contents of soluble solids (SS) (A and B), ascorbic acid (C and D) and titratable acidity (TA) (E and F) of crisp lettuce plants, cv. Isabela, grown organically (full symbol) or conventional (empty symbol), stored at $4^{\circ} \mathrm{C}$ and $90-95 \%$ relative humidity, fully open packaging ( $\left.\boldsymbol{\bullet}\right)$, partially closed $(\bullet)$ and fully closed ( $\left.\mathbf{\Delta}\right)$ ]. Dourados, UFGD, 2012.

das folhas e nos teores de clorofila, entre as temperaturas utilizadas.

A variação nos valores de $\mathrm{pH}$ foi pequena entre as alfaces orgânicas e convencionais, com redução até o $5^{\circ}$ dia de armazenamento, mantendo-se até o $8^{\circ}$ dia e aumentando em seguida até o final do armazenamento (Figura 1D). Resultados semelhantes também foram obtidos por Morais et al. (2011), ao avaliarem alface hidropônica sob efeitos de malhas de sombreamento, com diferentes percentagens de atenuação da radiação solar, constatando que por ocasião da colheita e após quatro dias de armazenamento refrigerado $\left(7,6 \pm 1^{\circ} \mathrm{C}\right.$ e $27 \pm 5 \%$ UR), houve pequena variação no $\mathrm{pH}$, entre os tratamentos e ligeiro aumento com o período de armazenamento. $\mathrm{O}$ aumento de $\mathrm{pH}$ durante $\mathrm{o}$ armazenamento, segundo Chitarra \& Chitarra (1990), pode estar relacionado ao desdobramento do amido em açúcares redutores e sua conversão em ácido pirúvico provocada pela respiração, como também está associado à redução de acidez em razão do amadurecimento, conforme pode ser verificado nos resultados de AT (Figuras 2E, 2F).

Quanto aos teores de SS ( ${ }^{\circ}$ Brix) não 
houve interação significativa entre os períodos de armazenamento, os tipos de cultivo e as embalagens. No entanto, verifica-se na tabela 2 que nas embalagens TA os teores foram significativamente maiores em relação às $\mathrm{TF}$ e não significativos para as PF. A diferença de teores em cada tipo de embalagem está relacionada, segundo Neres et al. (2004), ao aumento da concentração dos sólidos solúveis totais em função da perda de água.

Pela figura 2A, o cultivo orgânico apresentou aumento de SS até o $10^{\circ}$ dia, para decrescer até o $15^{\circ}$ dia. A figura 2B indica comportamento semelhante de SS pelo cultivo convencional, em relação ao orgânico, no entanto com aumento mais acentuado até o $10^{\circ}$ dia, e com maior redução até o $15^{\circ}$ dia. $\mathrm{O}$ aumento de SS, de acordo com Neres et al. (2004), ocorreu, provavelmente, em função do avanço do processo de maturação, além de outras alterações, como aumento na biossíntese de sólidos solúveis, como açúcares redutores e não redutores. Resultados semelhantes foram também obtidos por Morais et al. (2011) que constataram aumento no teor de SS em quatro dias de armazenamento refrigerado $\left(7,6 \pm 1^{\circ} \mathrm{C}\right.$ e $27 \pm 5 \%$ UR).

Segundo Kays (1991), a diminuição de SS ocorre com o aumento do período de armazenamento, quando se colhe um produto hortícola no ponto ótimo de maturação, pois servem como substrato respiratório. No entanto, o decréscimo de SS com maior magnitude nos produtos do cultivo convencional, pode estar relacionado pela maior deterioração (Tabela 1) em decorrência da própria senescência. A diferença de resposta nos teores de SS pelos cultivos convencional e orgânico, durante o período de armazenamento podem, de acordo com Chitarra \& Chitarra (2005) e Raupp et al. (2009), ser função de fatores diversos como cultivares, tipo de solo, condições climáticas e práticas culturais.

Com relação ao teor de AA, o cultivo orgânico (Figura 2C) apresentou, ao longo do armazenamento, um menor aumento em comparação ao convencional (Figura 2D), não tendo havido diferenças significativas para as embalagens TA e PF. Embora os produtos submetidos ao cultivo convencional tenham iniciado o armazenamento com menores teores de ácido ascórbico, a partir do $5^{\circ}$ dia, estes teores se tornaram maiores que nas alfaces produzidas pelo cultivo orgânico. Segundo Rocha (2010), o modo de cultivo pode interferir nos teores de diversas substâncias consideradas antioxidantes. A superioridade inicial do cultivo orgânico assemelha-se aos resultados obtidos por Williams (2002) e Chassy et al. (2006), ao encontrarem níveis significantemente maiores de ácido ascórbico em tomates orgânicos comparados com convencionais.

A maior perda de água por transpiração, verificada nos produtos submetidos ao cultivo convencional, refletiu em menor qualidade aparente durante o armazenamento. Por outro lado, resultou em maiores teores de AA em comparação ao cultivo orgânico. Estes resultados estão de acordo com Campos et al. (2008) e Rocha (2010), pois, segundo estes autores, a perda de água por transpiração leva a um aumento gradativo do teor de vitamina $\mathrm{C}$, resultante esta, da translocação contínua e síntese de ácido L-ascórbico proveniente do acúmulo de sólidos solúveis e açúcares redutores.

Quanto à acidez titulável (AT), verificou-se que o armazenamento, tanto dos produtos submetidos ao cultivo orgânico (Figura 2E), quanto convencional (Figura 2F), promoveram aumento de valores, com perfil semelhante, até o $8^{\circ}$ dia para os três tipos de embalagens, quando o cultivo convencional passou a apresentar reduções até o $15^{\circ}$ dia. $\mathrm{O}$ cultivo orgânico continuou com aumento de valores até o $10^{\circ}$ dia, e a partir de então com reduções até o final do armazenamento. A partir do $10^{\circ}$ dia de armazenamento, os teores de AT nas alfaces submetidas ao cultivo orgânico estiveram sempre superiores aos produtos submetidos ao cultivo convencional. $\mathrm{O}$ aumento de AT ocorrido até o $8^{\circ}$ e $10^{\circ}$ dia de armazenamento para os produtos submetidos ao cultivo convencional e orgânico, respectivamente, está de acordo com os resultados obtidos por Morais et al. (2011) os quais, ao armazenarem alface hidropônica sob refrigeração $\left(7,6 \pm 1^{\circ} \mathrm{C}\right.$ e $27 \pm 5 \%$ UR), também constataram aumento na AT após quatro dias de armazenamento. A diferença de resposta entre os dois cultivos a partir do $8^{\circ}$ dia pode ser devido ao grau de deterioração, que foi diferente entre os dois cultivos, e da composição química das plantas que, segundo Taiz \& Zeiger (2004), pode variar entre diferentes espécies e mesmo dentro de cada espécie, de acordo com as condições ambientais às quais elas foram submetidas.

As reduções na AT ocorridas nos dois cultivos podem estar relacionadas com o período de maturação, pois segundo Chitarra \& Chitarra (2005), após a colheita e durante o armazenamento, a concentração dos ácidos orgânicos usualmente declina em decorrência de sua utilização como substrato na respiração ou da sua transformação em açúcares.

De maneira geral, além dos maiores teores de SS e AT apresentados pelo cultivo orgânico, verifica-se uma tendência deste cultivo em conservar a qualidade aparente de alfaces por mais tempo, quando armazenadas sob refrigeração e acondicionadas em embalagens plásticas de polietileno de baixa densidade, o que demonstra potencialidades a serem avaliadas em outros trabalhos de pesquisa.

\section{REFERÊNCIAS}

ÁlVARES VS; FINGER FL; SANTOS RCA; SILVA JR; CASALI VWD. 2007. Effect of pre-cooling on the postharvest of parsley leaves. Journal of Food, Agriculture \& Environment 5: 31-34.

ÁLVARES VS; NEGREIROS JRS. 2010. Nota Científica. Pré-resfriamento e embalagem na conservação de folhas de salsa. Brazilian Journal of Food Technology 13: 107-111.

AMARANTE C; BANKS NH; GANESH S. 2001. Relationship between character of skin cover of coated pears and permeance to water vapour and gases. Postharvest Biology and Technology 21: 291-301.

ASSOCIATION OF OFFICIAL ANALYTICAL CHEMISTS. 1990. Official methods of the association of official analytical chemists. Washington: 1298p.

CAMPOS FM; MARTINO HSD; SABARENSE CM; PINHEIRO-SANT'ANA HM. 2008. Estabilidade de compostos antioxidantes em hortaliças processadas: uma revisão Alimentação e Nutrição 19: 481-490.

CHASSY AW; BUI L; RENAUD ENC; VAN HORN M; MITCHELL AE. 2006. A threeyear comparision of the content of antioxidant microconstituents and several quality characteristics in organic and conventionally managed tomatoes and bell peppers. Journal of Agricutural and Food Chemistry 54: 8244- 
8252.

CHITARRA MIF; CHITARRA AB. 1990. Póscolheita de frutos e hortaliças: fisiologia e manuseio. Lavras: ESAL/FAEPE. 293 p.

CHITARRA MIF; CHITARRA AB. 2005. Póscolheita de frutos e hortaliças: fisiologia e manuseio. Lavras: UFLA. 785p.

FRANÇA CFM. 2011. Conservação e qualidade pós-colheita em duas variedades de alfaces submetidas ao hidroresfriamento. Viçosa: UFV. 44p (Dissertação mestrado).

GUADAGNIN SG; RATH S; REYES FGR. 2005. Evaluation of the nitrate content in leaf vegetables produced through different agricultural systems. Food Additives and Contaminants 22: 1203-1208.

HENZ GP; SUINAGA F. 2009. Tipos de alface cultivadas no Brasil. Brasília: Embrapa Hortaliças. 7p. (Comunicado Técnico, 75).

INSTITUTO ADOLFO LUTZ. 1985. Normas analíticas, métodos químicos físicos para análise de alimentos. São Paulo: IAL. 533p.

KAYS SJ. 1991. Postharvest physiology of perishable plant products. New York: Van Nostrand Reinhold. 453p.

KAYS SJ. 1999. Preharvest factors affecting appearance. Postharvest Biology and Technology 15: 233-247.

MARCHIORI JMG. 2006. Qualidade nutricional dos queijos mussarela orgânico e convencional elaborados com leite de búfala e de vaca. Araraquara: UNESP. 54p (Tese mestrado).
MELLO JC; DIETRICH R; MEINERT EM; TEIXEIRA E; AMANTE ER. 2003. Efeito do cultivo orgânico e convencional sobre a vida de prateleira de alface americana (Lactuca sativa) minimamente processada. Ciência e Tecnologia de Alimentos 23: 418-426.

MORAIS PLD; DIAS NS; ALMEIDA MLB; SARMENTO JDA; SOUSA NETO ON. 2011. Qualidade pós-colheita da alface hidropônica em ambiente protegido sob malhas termorefletoras e negra. Revista Ceres 58: 638-644.

MOTA WF; FINGER FL; CECON PR; SILVA DJH; CORREA PC; FIRME LP; NEVES LLM. 2006. Armazenamento de frutos de quiabo embalados com filme de PVC em condição ambiente. Horticultura Brasileira 24: $255-258$.

NERES CRL; VIEIRA G; DINIZ ER; MOTA WF; PUIATTI M. 2004. Conservação do jiló em função da temperatura de armazenamento e do filme de polietileno de baixa densidade. Bragantia 63: 431-438.

PARK KW; KANG HM; YANG EM; JUNG JC. 1999. Effects of film package and storage temperature on the quality of parsley in modified atmosphere storage. Acta Horticulturae 483: 291-298.

RAUPP DS; GARDINO JR; SCHEBESKI LS; AMADEU CA; BORSATO AV. 2009. Processamento de tomate seco de diferentes cultivares. Acta Amazonica 39: 415-422.

REZENDE GM; YURI JE; SOUZA RJ. 2007.
Épocas de plantio e doses de silício no rendimento de alface tipo americana. Horticultura Brasileira 25: 455-459.

ROCHA SA. 2010. Antioxidantes em vegetais pós-colheita de origem orgânica. Botucatu: UNESP. 103p (Tese doutorado).

SALA FC; COSTA CP. 2012. Retrospectiva e tendência da alfacicultura brasileira. Horticultura brasileira 30: 187-194.

SAMPAIO RA; RAMOS SJ; GUILHERME DO; COSTA CA; FERNANDES LA. 2008. Produção de mudas de tomateiro em substratos contendo fibra de coco e pó de rocha. Horticultura Brasileira 26: 499-503.

SANTI A; CARVALHO MAC; CAMPOS OR; SILVA AF; ALMEIDA JL; MONTEIRO S. 2010. Ação de material orgânico sobre a produção e características comerciais de cultivares de alface. Horticultura Brasileira 28: 87 - 90.

SILVA EMNCP; FERREIRA RLF; ARAÚJO NETO SEA; TAVELLA LB; SOLINO AJS. 2011. Qualidade de alface crespa cultivada em sistema orgânico, convencional e hidropônico. Horticultura brasileira 29: 242-245.

TAIZ L; ZEIGER E. 2004. Fisiologia vegetal. $3^{\text {a }}$ ed., Porto Alegre: Artmed. 720p.

WILLIAMS CM. 2002. Nutritional quality of organic food: shades of grey or shades of green? Proceedings of the Nutrition Society 61: 19-24. 